\title{
A Review on the National Culture and Its Effects on the Transportation Safety Perspectives
}

\author{
Y. Kwon \\ Chosun University, Gwangju, South Korea
}

\begin{abstract}
Safety, along with the issue of security, is the most substantial and critical issue to any society and nation of the mankind. The fact that human elements contribute dominantly, in particular, to the transportation - marine, air and road traffic - accidents requires not only the technical approaches, but also cultural configuration inherent to the accidents. This paper tries to incorporate Hofstede's dimensions of national culture to identify possible interaction with accidents. It will be of help to figure out the need to consider the aspect of national culture to be efficient in dealing with policies for safer communities and nations.
\end{abstract}

\section{INTRODUCTION}

It is well known that Korea (Republic of) has achieved dramatic economic development since the Korean War. It also achieved political democracy through numerous and painful civil movements in 1970s and 1980s. In fact, the world now expects Korea to contribute in various fields regarding global issues and it is anticipated that Korea would willingly take part in with an active and efficient manner. Present 'peace talks' with North Korea is, for instance, one of the main movements of Korea for the international welfare and peace.

Nevertheless, as far as the issue of safety in Korea is concerned, there is room for much improvement. The author suspects that few Koreans recognize the importance of safety of the community and/or society. For a couple of decades, at least, Korean government has been trying to establish safe environments, remedies and enforcements, but failed. This is due to, the author believes, the missing premise that 'safety is a matter of culture before of technology (Kwon 2012)'. Simple remedy of asking individual responsibility with at most temporary extra budget, for example, cannot help, but recurring the accidents.

Reason (1997) argues that organizational accidents, which often leads to catastrophic consequences, is the main concern of the safety issue. He includes talks on organizational culture as well as safety culture, but not on the national culture. It is apprehended that Korea does not recognize the Reason's argument, let alone the national culture.

\subsection{Cultures within safety}

Culture could be defined as the aggregation of peoples' thought and behavior in a given community/society/country. Naturally, it yields individual, organizational and national cultures. In fact, culture is an aggregate of human factors (Kwon 2012). In the context, it may be argued that most modern civilization, such as technologies, institutions, skills relevant to safety issues and so on, is western products, which are, then, imported by the rest of countries. Such know-hows are developed based on 
western culture and if, once established, it does not work properly or even does not attract active interest in another society or country, we may speculate upon the differences of culture between the societies/countries. It is noted that Hofstede \& Hofstede (2005) and Merritt (2000) ask the same questions.

In short, one of the challenges to tackle the current safety level of Korean society is to change the 'practices' consulting the core 'values' of the society. This paper tries to contribute for the task reviewing and comparing national cultures between vulnerable and advanced countries with respect to road traffic safety records. It may also be noted that road traffic activity is the most common daily life of the people and, therefore, raising its safety practices is the most efficient way to achieve safer environment/society, considering its ripple effect on the whole community, including sea and/or air transportation safety circles.

\section{NATIONAL CULTURE AND ITS DIMENSIONS}

\subsection{National Culture}

Geert Hofstede carried out pioneering works on national culture during late 1960's through 1970s. His research has been updated by himself, his son Gert Jan and Michael Minkov (Hofstede et al. 2014). Figure 1 depicts the manifestations of culture at different levels of depth (Hofstede \& Hofstede 2005). In practice, we may focus on 'Values' (which is the deepest one) and 'Practices' in a community/society. Practices, being comprised of rituals, heroes and symbols, are visible to an outside observer; their cultural meaning, however, is invisible and lies precisely and only in the way these practices are interpreted by the insiders. Culture change can be fast for the practices, whereas it is slow for values. Values are broad tendencies to prefer certain states of affairs over others. Values are feelings with an arrow to it: a plus and minus side dealing with, for instance, evil vs good, dangerous vs safe, forbidden vs permitted, moral vs immoral, and so on (Hofstede \& Hofstede 2005).

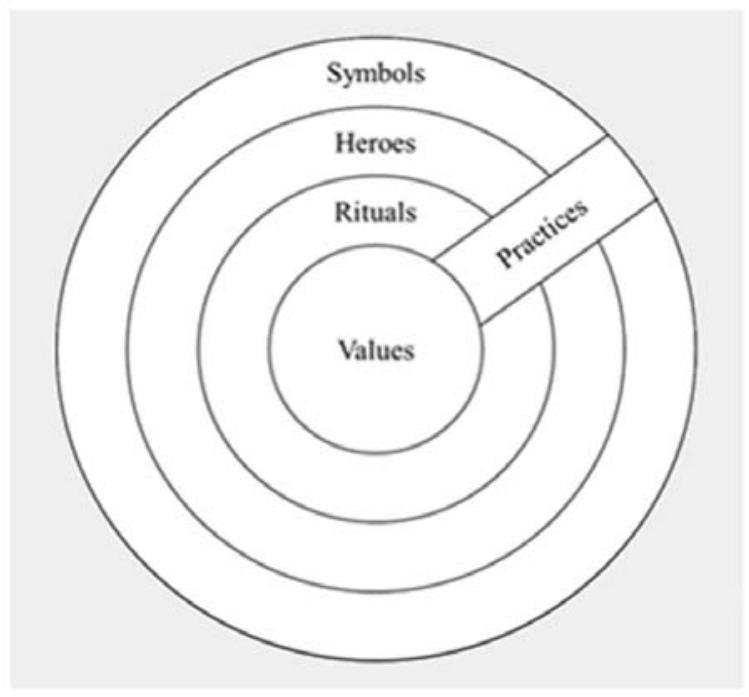

Figure 1. The "Onion": manifestations of culture at different level of depth (Hofstede \& Hofstede 2005)
Figure 2 shows the learning process of values and practices. Values are acquired early in our lives. As we grow up at some 10 to 12 years, we can quickly, largely and unconsciously absorb necessary information from our environment. Then, at the end of this period, we gradually switch to a different, conscious way of learning, focusing primarily on new practices. It is noted that basic values, being acquired at early ages, become considerably stable in spite of sweeping changes in practices (Hofstede \& Hofstede 2005).

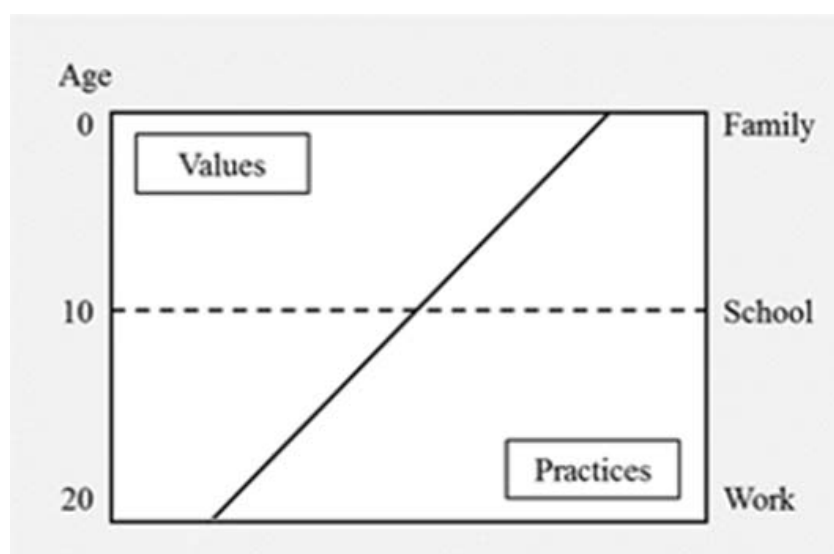

Figure 2. The learning of values and practices (Hofstede \& Hofstede 2005)

\subsection{Dimensions of National Culture}

A dimension is an aspect of a culture that can be measured relative to other cultures. Having studied survey data about the values of people working at IBM in more than fifty countries and consulted with findings of social scientists, such as Alex Inkeles and Daniel Levinson, Hofstede found four basic problem areas represent dimensions of cultures. Later on, with the help of colleagues, two dimensions are supplemented, resulting in as follows (Hofstede et al. 2014);

1 Power distance index (PDI)

2 Individualism index (IDV)

3 Masculinity index (MAS)

4 Uncertainty avoidance index (UAI)

5 Long-term orientation (LTO)

6 Indulgence versus restraint (IVR)

PDI scores are about 'dependence' relationships in a country, and can be defined as 'the extent to which the less powerful members of institutions and organizations within a country expect and accept that power is distributed unequally'. It is noted that largepower-distance countries show a pattern of polarization between dependence and counterdependence and the emotional distance between subordinate and their bosses is large.

As to the IDV, individualism pertains to societies in which the ties between individuals are loose. Collectivism as its opposite pertains to societies in which people from birth onward are integrated into strong, collective in-groups, which throughout people's lifetimes continue to protect them in exchange for unquestioning loyalty. 
The terms masculine and feminine are used for social, culturally determined roles. A society is called masculine/feminine when emotional gender roles are clearly distinct/overlapped. It may also be interpreted as the desirability of assertive behavior against the desirability of modest behavior, respectively.

Uncertainty avoidance can be defined as the extent to which the members of a culture feel threatened by ambiguous or unknown situations. Hofstede \& Hofstede (2005) state that stronger uncertainty avoidance means faster driving, that is more fatal accidents.

LTO stands for the fostering of virtues oriented toward future rewards - in particular, perseverance and thrift. Short-term orientation stands for the fostering of virtues related to the past and present - in particular, respect for tradition, preservation of 'face' and fulfilling social obligations.

Indulgence represents the tendency toward allowing relative freedom of fulfilling substantial and natural ambition of human being related with having fun and enjoying life. Restraint shows against such freedom by regulation and control.

Hofstede et al. (2014) also provide key differences between small- and large distances societies on each dimension with categorizing such as 'general norm and family', 'language, personality, and behavior', 'school and the workplace' etc., which are quite informative on the main practices in a given dimension and country. Selections of these key differences, which are relevant to safety issues directly and indirectly, are recounted and incorporated, respectively, for the assessing the results to be of help in drawing long-term resolutions. It is noted that even in a country, distances can be quite different with social class, education level, and occupation as well as with gender and generation.

\section{NATIONAL CULTURES OF COUNTRIES ON ROAD TRAFFIC SAFETY RECORDS}

\subsection{Relation between road traffic safety and national culture dimensions}

Effects of the car, being the most popular mode of transport worldwide, is tremendous on a society (Kang 2011a). Such effects would reflect the values of a community and again through the practices give effects to the values of national culture. Poor traffic safety culture is comprised of not only irresponsible/inconsiderable behavior, lack of attention, aggressive behavior but also poor design and construction on either roads or signal facilities as well as impracticable plan to deal with relevant issues. These typical characteristics of a poor traffic culture are only due to selfishness (and not due to individualism). Selfishness comes mainly from lack of communication, which is an essence of all human activities, including traffic in particular (Min \& Noh 2011, Cheong 2007). Then it would be important why and how lack of communication happens in a community/society. With the help of one's own experiences as well as information about key differences between small- and large distances societies on each dimension, Hofstede et al. (2014) provided, we may observe the practical mechanism of a poor traffic culture.

Each of 5 countries with poor/advanced road traffic fatality record, named as 'vulnerables'/'advanced' respectively are designated from the data shown in Figures 1, 2 and 3 (OECD/ITF 2018), and they are as follows;

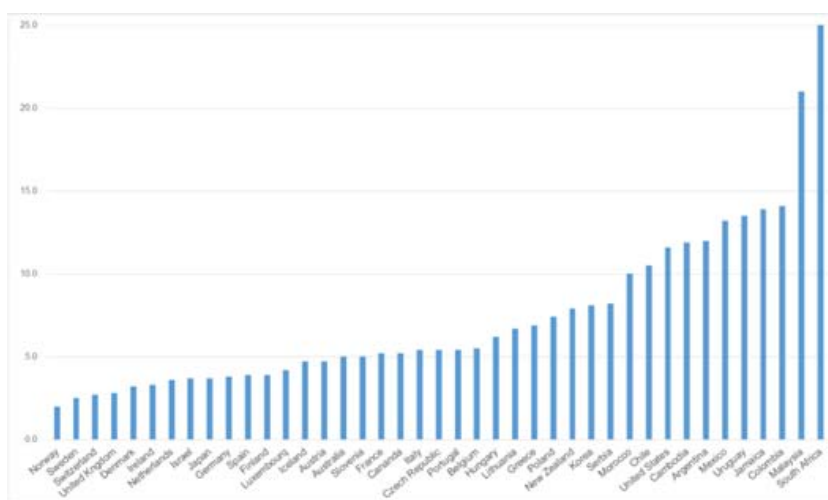

Figure 3. Road fatalities per 100,000 inhabitants 2017 (OECD/ITF 2018)

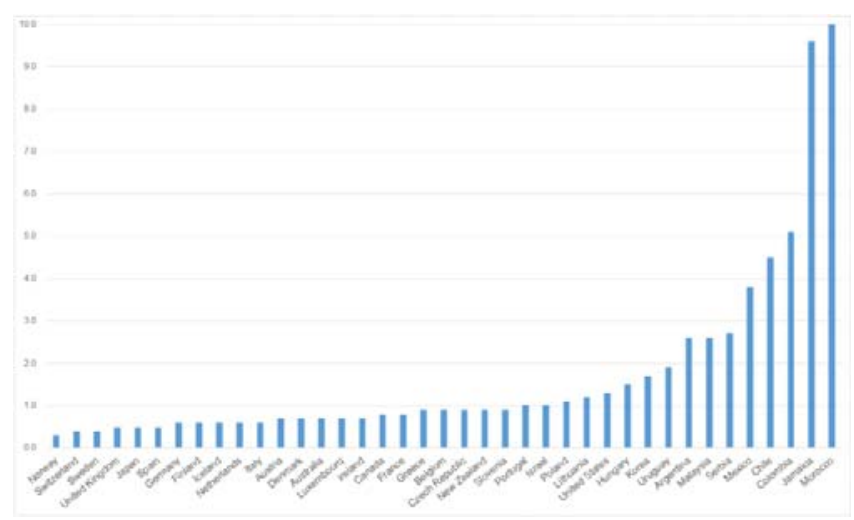

Figure 4. Road deaths per 10,000 vehicles 2016 (OECD/ITF 2018)

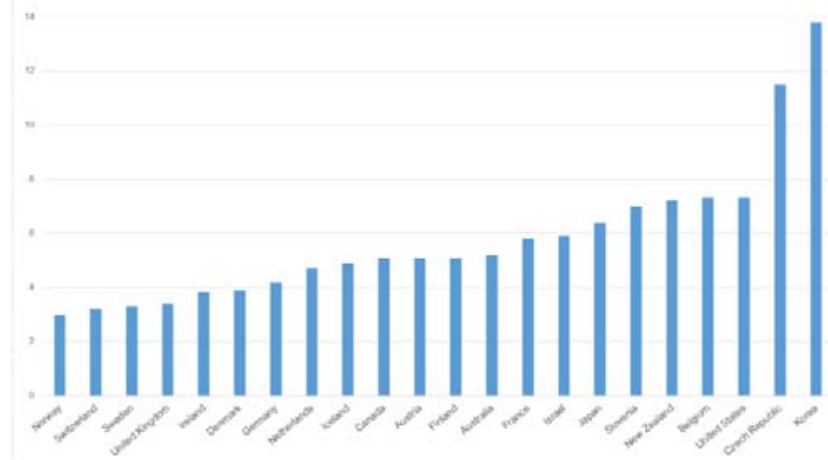

Figure 5. Road deaths per distance travelled 2016: billion vehicle-kilometres (OECD/ITF 2018)

- Vulnerable: Korea (Republic of), Chile, Colombia, Malaysia and South Africa (Republic of)

- Advanced: United Kingdom, Sweden, Netherlands, Norway and Switzerland

It is noted that only certain countries are considered who provided data to the International Traffic Safety Data and Analysis Group (IRTAD) and whose national culture dimensions are available. 


\subsection{National cultures of vulnerable and advanced countries}

Figures 6 through 11 show the comparison between 'vulnerables' and 'advanced' of each dimension of national culture (Hofstede et al. 2014). It is noted that in cases of Switzerland and South Africa, the Hofstede's dimension indices are mean values of French and German territories and from whites only, respectively.

Figure 6 shows higher power distance values for vulnerable countries. Considering substantial differences between small- and large-power-distance societies shown in Table 1, it is presumed the result is plausible. Misuse of power appears in traffic activities, as Kang (2011a) speculated, and it would be severe in large PDI countries as shown in Table 1. More power distance, less dialogue is a critical issue as traffic, being road, air or marine, is all about dialogue (or communication) with one another.

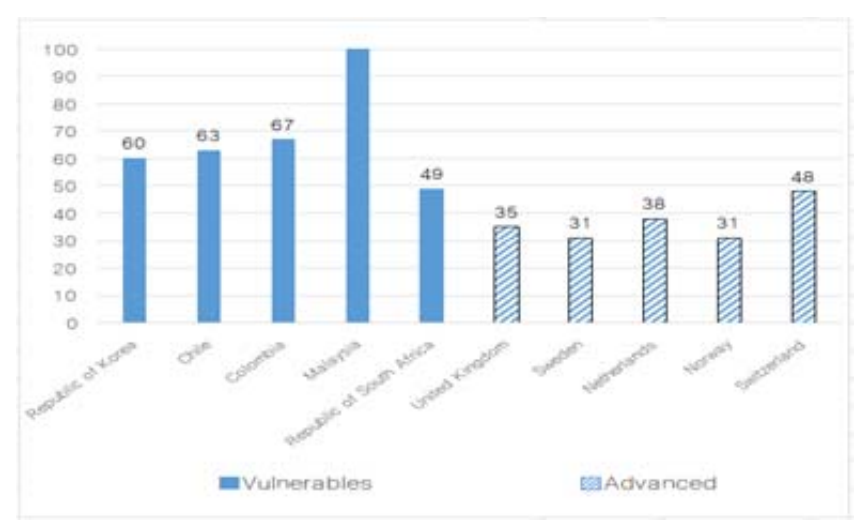

Figure 6. Power distance index (PDI)

Table 1. Selections of key differences between small- and large-power-distance societies: The State (Hofstede \& Hofstede 2005)

\begin{tabular}{ll}
\hline Small Power Distance & Large Power Distance \\
\hline $\begin{array}{l}\text { The use of power should be } \\
\text { legitimate and follow criteria } \\
\text { of good and evil. }\end{array}$ & $\begin{array}{l}\text { Might prevails over right: } \\
\text { whoever holds the power is } \\
\text { right and good. }\end{array}$ \\
$\begin{array}{ll}\text { All should have equal rights. } \\
\text { The powerful should have } \\
\text { privileges. }\end{array}$ \\
$\begin{array}{l}\text { Power is based on formal } \\
\text { position, expertise, and ability } \\
\text { to give rewards. }\end{array}$ & $\begin{array}{l}\text { Power is based on tradition } \\
\text { ability to use force. }\end{array}$ \\
$\begin{array}{l}\text { There is more dialogue and } \\
\text { less violence in domestic } \\
\text { politics. }\end{array}$ & $\begin{array}{l}\text { There is less dialogue and } \\
\text { more violence in domestic } \\
\text { politics. }\end{array}$ \\
\hline
\end{tabular}

Comparison of individualism index is quite evident as shown in Figure 7. The more collectivism, the more vulnerable in road traffic safety accidents. Hofstede \& Hofstede (2005) refer to Bond's survey study results that students from countries scoring 'individualist' and 'collectivist' answered that following values, respectively, were particularly important:

- Tolerance of others

- Harmony with others

- Noncompetitiveness

- Trustworthiness

- Contentedness with one's position in life and
- Filial piety (obedience to parents, respect for parents, honoring of ancestors, financial support of parents)

- Patriotism

Bond's results above correlate strongly with the result in Figure 7. Several key differences between collectivist and individualist societies shown in Table 2 are also to be noted as the cause and effect of driving culture (Kang 2011a).

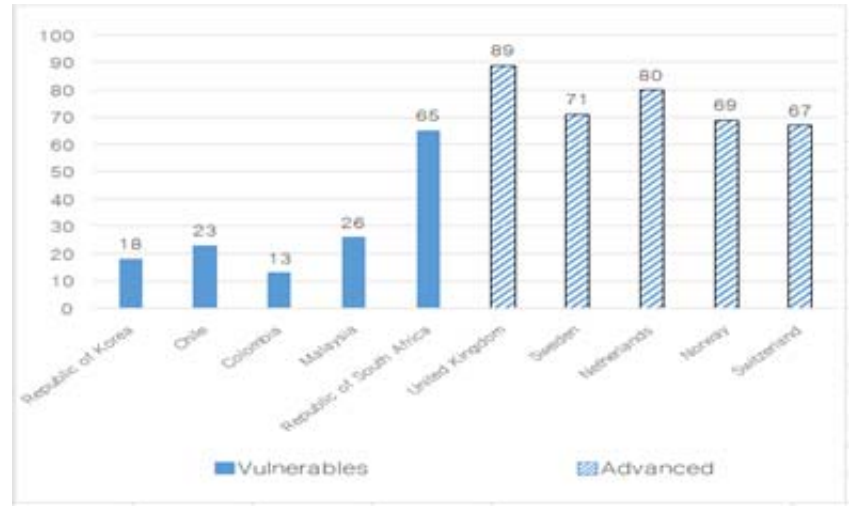

Figure 7. Individualism index (IDV)

Table 2. Selections of key differences between collectivist and individualist societies: General norm, Personality, school, workplace, The State (Hofstede \& Hofstede 2005)

\begin{tabular}{ll}
\hline Collectivist & Individualist \\
\hline $\begin{array}{l}\text { Trespassing leads to shame } \\
\text { and loss of face for self and }\end{array}$ & $\begin{array}{l}\text { Trespassing leads to guilt } \\
\text { and loss of self-respect. }\end{array}$
\end{tabular}
group.

Interdependent self

Independent self

The purpose of education is learning how to do.

The purpose of education is learning how to learn.

In-group customers get better Every customer should get treatment (particularism). the same treatment (universalism).

Private life is invaded by group(s)

Laws and rights differ by group.

Everyone has a right to privacy

Laws and rights are supposed to be the same for all.

The result of masculinity index shows certain correlation, but the United Kingdom and Switzerland appear to be quite exceptional among the advanced, as shown in Figure 8. Otherwise, it is tempting to draw more masculinity, more vulnerable to road accidents. It is suspected, from author's experience, that the UK (as well as Switzerland, particularly at German region) preserves strong disciplines along the established social principles. Such discrepancies may arise from racial characteristics. Speculating the definition of MAS and consulting more data of other countries, masculinity/femininity may not significantly related with road traffic safety. 


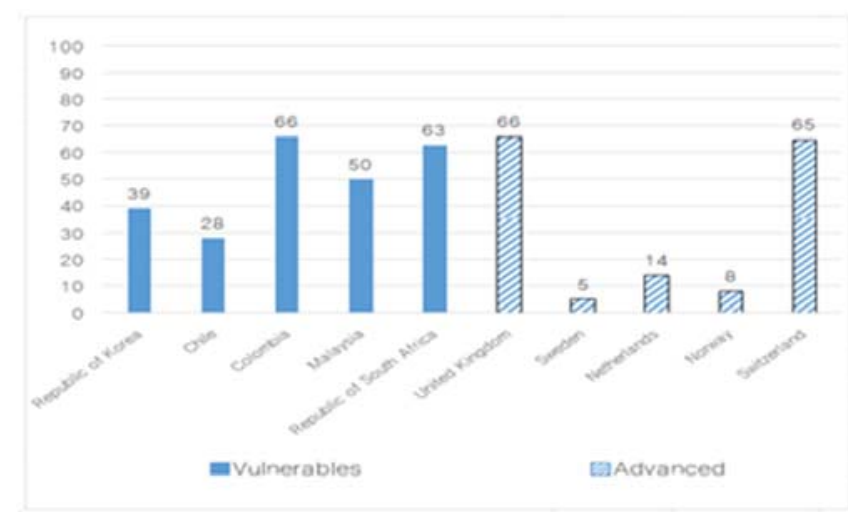

Figure 8. Masculinity index (MAS)

The result of uncertainty avoidance index, Figure 9, reveals visible differences between two groups, as Hofstede \& Hofstede (2005) speculated that stronger uncertainty avoidance means faster driving. In fact, it is revealed that the degree of uncertainty avoidance is a very important issue even in safety perspectives. Numerous examples of general practices are shown in Table 3-1 through 3-5, which are directly and indirectly relevant to safety practices. Kang (2011b) argues that at the background of the, so called, speed war in Korea, fears to the endless uncertainty locate, disabling communication.

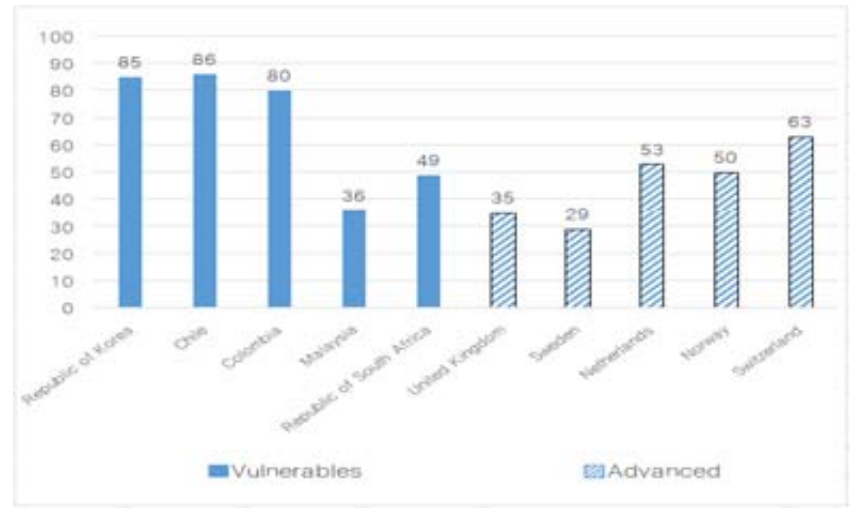

Figure 9. Uncertainty avoidance index (UAI)

Figure 10 shows the result of long term orientation, from which LTO may not be relevant to road traffic accidents.

The result of indulgence versus restraint (IVR) does not look to show relation to safety behavior. Nevertheless, Korea is a unique case in the example, which might need extra attention.
Table 3-1. Selections of key differences between weak and strong uncertainty avoidance societies: General norm and family (Hofstede \& Hofstede 2005)

Weak uncertainty avoidance Strong uncertainty avoidance

Uncertainty is a normal The uncertainty inherent in feature of life, and each day life is a continuous threat

is accepted as it comes. that must be fought.

Low stress and low anxiety. High stress and high anxiety.

Aggression and emotions should not be shown

Aggression and emotions may at proper times and places be ventilated.

Comfortable in ambiguous Acceptance of familiar risks; situations and with unfamiliar fear of ambiguous situations risks. and of unfamiliar risks.

Weak superegos developed. Strong superegos developed.

Similar modes of address for Different modes of address different others. for different others.

What is different is curious. What is different is dangerous.

Family life is relaxed. Family life is stressful.

Table 3-2. Selections of key differences between weak and strong uncertainty avoidance societies: Health and education (Hofstede \& Hofstede 2005)

\begin{tabular}{|c|c|}
\hline Weak uncertainty avoidance & $\begin{array}{l}\text { Strong uncertainty } \\
\text { avoidance }\end{array}$ \\
\hline People feel happier. & People feel less happy. \\
\hline $\begin{array}{l}\text { People have fewer worries } \\
\text { about health and money. }\end{array}$ & $\begin{array}{l}\text { People have more worries } \\
\text { about health and money. }\end{array}$ \\
\hline $\begin{array}{l}\text { Students are comfortable with } \\
\text { open-ended learning } \\
\text { situations and concerned } \\
\text { with good discussions. }\end{array}$ & $\begin{array}{l}\text { Students are comfortable in } \\
\text { structured learning } \\
\text { situations and concerned } \\
\text { with right answers. }\end{array}$ \\
\hline $\begin{array}{l}\text { Results are attributed to a } \\
\text { person's own ability. }\end{array}$ & $\begin{array}{l}\text { Results are attributed to } \\
\text { circumstances and luck. }\end{array}$ \\
\hline Teachers involve parents. & Teachers inform parents. \\
\hline
\end{tabular}

Table 3-3. Selections of key differences between weak and strong uncertainty avoidance societies: The workplace, organization, and motivation (Hofstede \& Hofstede 2005)

\begin{tabular}{ll}
\hline Weak uncertainty avoidance & $\begin{array}{l}\text { Strong uncertainty } \\
\text { avoidance }\end{array}$ \\
\hline $\begin{array}{l}\text { There should be no more } \\
\text { rules than strictly necessary. }\end{array}$ & $\begin{array}{l}\text { There is an emotional need } \\
\text { for rules, even if these will } \\
\text { not work. }\end{array}$ \\
$\begin{array}{l}\text { Hard-working only when } \\
\text { needed. }\end{array}$ & $\begin{array}{l}\text { There is an emotional need } \\
\text { to be busy and an inner urge } \\
\text { to work hard. }\end{array}$ \\
$\begin{array}{l}\text { There is tolerance for } \\
\text { ambiguity and chaos. }\end{array}$ & $\begin{array}{l}\text { There is a need for precision } \\
\text { and formalization. }\end{array}$ \\
$\begin{array}{l}\text { Belief in generalists and } \\
\text { common sense. }\end{array}$ & $\begin{array}{l}\text { Belief in experts and } \\
\text { technical solutions. }\end{array}$ \\
Top managers are concerned & $\begin{array}{l}\text { Top managers are } \\
\text { concerned with daily } \\
\text { with strategy. }\end{array}$
\end{tabular}


Table 3-4. Selections of key differences between weak and strong uncertainty avoidance societies: The citizen and the state (Hofstede \& Hofstede 2005)

Weak uncertainty avoidance Strong uncertainty avoidance

If laws cannot be respected, Laws are necessary, even if they should be changed. they cannot be respected.

Fast result in case of appeal Slow result in case of appeal to justice.

Citizens competent toward authorities. to justice.

Citizens incompetent toward authorities.

Citizen protest is acceptable.

Citizens trust politicians, civil servants, and the legal system.

There is high participation in voluntary associations and movements.

Citizen protest should be repressed.

Citizens are negative toward politicians, civil servants, and the legal system.

There is low participation in voluntary associations and movements.

Positive attitudes toward young people.

Tolerance, even of extreme ideas.

Negative attitudes toward young people.

Extremism and repression of extremism.

Table 3-5. Selections of key differences between weak and strong uncertainty avoidance societies: Tolerance and ideas (Hofstede \& Hofstede 2005)

Weak uncertainty avoidance Strong uncertainty avoidance

More ethnic tolerance.

Lower risk of violent intergroup conflict.

If commandments cannot be respected, they should be changed.

In philosophy and science, there is a tendency toward relativism and empiricism.

Scientific opponents can be personal friends.

Literature dealing with fantasy worlds.

More ethnic prejudice.
High risk of violent
intergroup conflict.

If commandments cannot be respected, we are sinners and should repent.

In philosophy and science, there is a tendency toward grand theories.

Scientific opponents cannot be personal friends.

Literature dealing with rules and Truth.

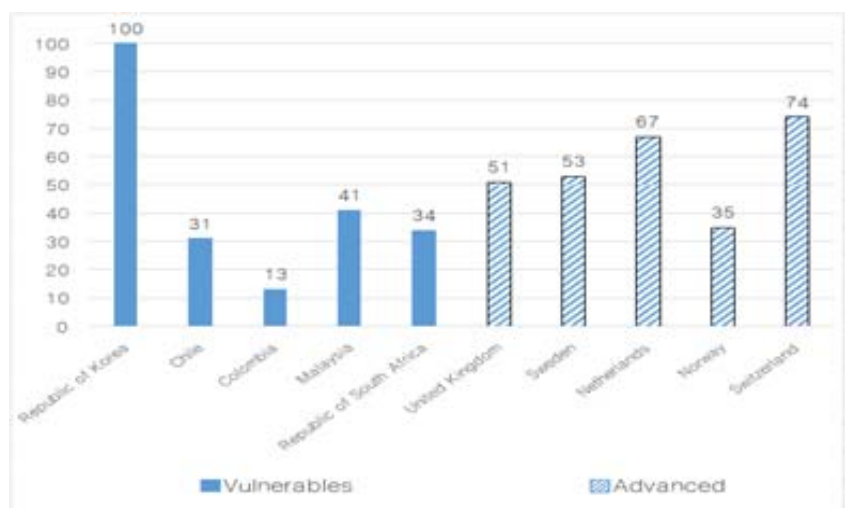

Figure 10. Long term orientation (LTO)

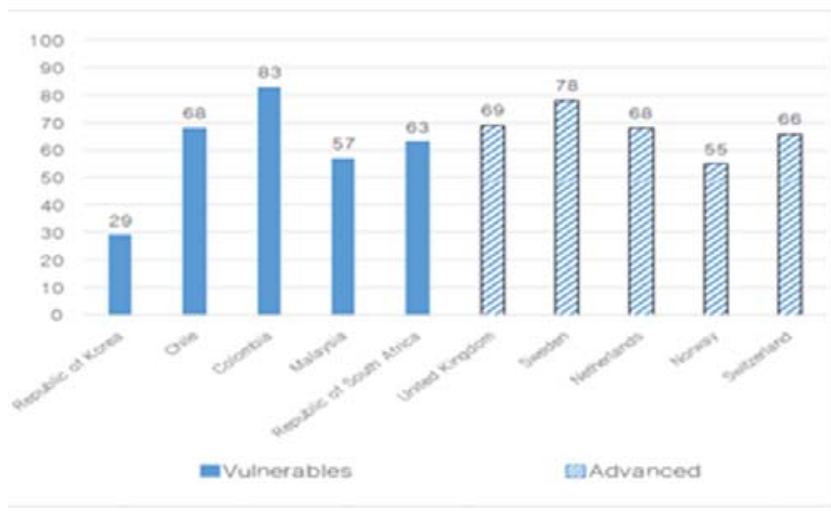

Figure 11. Indulgence versus restraint (IVR)

\section{DICUSSIONS}

There are a number of meetings to discuss the ways of enhancing the road traffic safety in Korea. It includes at times talks on the (road safety) culture, but comparing with corresponding contents of human and social scientists sectors, the approaches and development fall rather short. Even an ancient Chinese philosopher at BC 6 century, Lao-tzu claimed '不罰衆策', meaning 'the people commit, then not guilty' (Shin 2004).

Hofstede et al. (2014) enumerate differences between countries along value dimensions, which help not only understanding differences in thinking, feeling and behaving by the leaders and those led but also appreciating the theories produced or adopted in these countries to explain or prescribe thought, feeling, and behavior. Before entering in the present discussions, the author may confess about the hindrance he felt in some aspects. For instance, as to the definition of individualism or masculinity, the author had to try to overcome prejudice, probably most Koreans would have (Cheong 2007). In some cases, understanding terminology rightly is not easy job to outsiders. Also, the author realizes that he should have had good knowledge on the culture of the countries in order to be fair and logical in the investigation. Nevertheless, practices (of road traffic safety) being, in principle, from values the country and citizen move with, the result could be further discussed for Korea, the author's homeland.

Among the six dimensions, power distance, individualism and uncertainty avoidance appear to be related with traffic safety culture. Typical practices of these dimensions, shown in Tables 1, 2 and 3-1 through 3-4, are correlated directly and indirectly with features of traffic safety culture and practices. This implies that, in order to raise the traffic safety level, not only conventional technical approaches but also cultural aspects should be incorporated together. Well, the thing is that most safety experts and researchers would recognize, but it is not easy task at all to encompass it into the practices with which all stakeholders observe the need and accountability.

Hofstede \& Hofstede (2005) found that PDI score is related with (1) the country's geographic latitude (which is a rough indication to its climate), (2) its population size, and (3) its wealth, whereas as to the 
INV score (1) the country's geographic latitude and (2) its wealth are fairly associated. They also contend that differences in power distance as well as individualism-collectivism differences will survive for a long time into the future.

After all, in order to tackle the issues of power distance and individualism Korea encounters, communication and trust should be the answer after all, and they being the cause and effect, the way to looking forward to democracy and taking step by step, not in a hurry, would be the most efficient and effective policy. The progress might take much more time than as planned, but it is promising for Korea as to raising the safety level in the future, as power distance would become smaller and individualism gets more favor as ever in the society.

Uncertainty avoidance is a very substantial issue in a society. Reviewing and comparing the histories of contrasting ancient Roman and Chinese government types, Hofstede \& Hofstede (2005) speculated that expectations of fundamental changes in uncertainty avoidance difference should be a modest one, even though war and economic processes can play a role. Historically, Korea suffered difficulties even in modern era, such as colonialization, war, continuing north-south tensions, domestic political upheaval and dynamic economic growth, all of which should have affected the national anxiety level. But, there comes to shed light, fortunately, of social welfare system getting into full shape and of radical peace talks with North Korea. Such movements shall contribute to the Korean society easing the anxiety level in the future.

\section{CONCLUSIONS}

1 A national policy is based on its own national culture, and may not work on other nations. The same goes to the so called know-how of safety measures and policies.

2 National culture may well be incorporated in dealing with raising safety measures and developments along with conventional approaches including technical catch up.

3 It confirms that safety in a society comes in line with social trust and communication. Then institutions and measures for raising the safety may be drawn encompassing the conditions and environment of trust and communication consulting its own national culture. The effect could be rather slow, if not steady, but eventually progressive and efficient.

4 Raising the road traffic safety would be the most efficient way for the entire society, considering its ripple effects not only on the other transportation modes but also on social premises and even security

\section{REFERENCES}

Cheong, Soo-Bok. 2007. Korean Cultural Grammar. Saenggageuinamu (in Korean)

Hofstede, G. \& Hofstede, G.J. 2005. Cultures and Organizations. McGrow-Hill

Hofstede, G. Hofstede, G.J. \& Minkov, M. 2014. Culture and Organizations: Software of the Mind. Korean edition. Hakjisa (in Korean)

Kang, J. 2011a. Korea, an extraordinary country. Inmulgwasasangsa (in Korean)

Kang J. 2011b. Political Economy of Communication: A study on the structured factors of the communication disorder. Communication crisis of the Korean society, The Korean Society for Journalism \& Communication Studies. Communication Books (in Korean)

Kwon, Y. 2012. A Review of the Safety Culture for Developing Maritime Safety. Proceedings of the Conference on Education \& Professional Development, Southampton, UK

Merritt, A. 2000. Culture in the Cockpit: Do Hofstede's Dimensions Replicate? Journal of Cross-Cultural Psychology 31(3): 228-301

Min, Y. \& Noh, S.J. 2011. Conditions of Communication: A study on the political conversation between citizens of Korean society. Communication crisis of the Korean society, The Korean Society for Journalism \& Communication Studies. Communication Books (in Korean)

OECD/ITF. 2015. Road Safety Annual Report. OECD Publishing, Paris. http://dx.doi.org/10.1787/irtad-2015-en

OECD/ITF. 2018. Road Safety Annual Report 2015. OECD Publishing, Paris. www.itf-oecd.org/road-safety-annualreport-2018

Reason, J. 1997. Managing the Risks of Organizational Accidents, Ashgate

Shin, Y.B. 2004. Lecture: My reading of oriental classics. Dolbegae (in Korean) 